\title{
U.S. Department of the Interior South Central Climate Science Center
}

\section{What is a Climate Science Center?}

On September 14, 2009, the Secretary of the Interior signed a Secretarial Order (No. 3289) entitled, "Addressing the Impacts of Climate Change on America's Water, Land, and Other Natural and Cultural Resources." The Order effectively established the U.S. Department of the Interior (DOI) Climate Science Centers (CSCs) for the purpose of integrating DOI science and management expertise with similar contributions from our partners to provide information to support strategic adaptation and mitigation efforts on public and private lands across the United States and internationally.

\section{Planning for Climate Change Research}

CSCs are research collaborations guided by a U.S. Geological Survey (USGS) Center Director and hosted by a university or consortium of universities. Each CSC brings together expertise from university and federal scientists to support climate change research and collaborations in a specific geographic area.

Priority science activities of the CSCs include the following:

- Development of standardized approaches to monitoring, data management, modeling, and decision support;

- Use and creation of high-resolution climate information and derivative products to produce key information that is needed to forecast ecological and population responses at national, regional, and local levels;

- Integration of physical climate models with ecological-, habitat-, and population-response models;

- Development of models to predict fish- and wildlife-population and habitat changes; and

- Development of methods to assess vulnerability of species and habitats.

Boundaries of the CSCs are intended to be flexible depending on the science needs of a particular region. Because environmental science needs related to climate do not stop at political borders, science programs focused on natural resources also cannot be held to fixed borders. Likewise, the scientific capabilities of the CSCs will be directed toward meeting research needs, exclusive of geographic delineations.

\section{About the South Central Climate Science Center}

The South Central Climate Science Center (SC CSC) is supported by a consortium of partners that include The University of Oklahoma, Texas Tech University, Louisiana State University, The Chickasaw Nation, The Choctaw Nation of Oklahoma, Oklahoma State University, and the National Oceanic and Atmospheric Administration's Geophysical Fluid Dynamics Laboratory. Additionally, the SC CSC will collaborate with a number of other universities, State and federal agencies, and nongovernmental organizations (NGOs) with interests and expertise in climate science. The primary partners of the SC CSC are the Landscape Conservation Cooperatives (LCCs), which include the Desert, Eastern Tallgrass Prairie and Big Rivers, Great Plains, Gulf Coast Prairie, Gulf Coastal Plains and Ozarks, and Southern Rockies. CSC collaborations are focused on common science priorities that address priority partner needs, eliminate redundancies in science, share scientific information and findings, and expand understanding of climate change impacts in the south-central United States and Mexico.

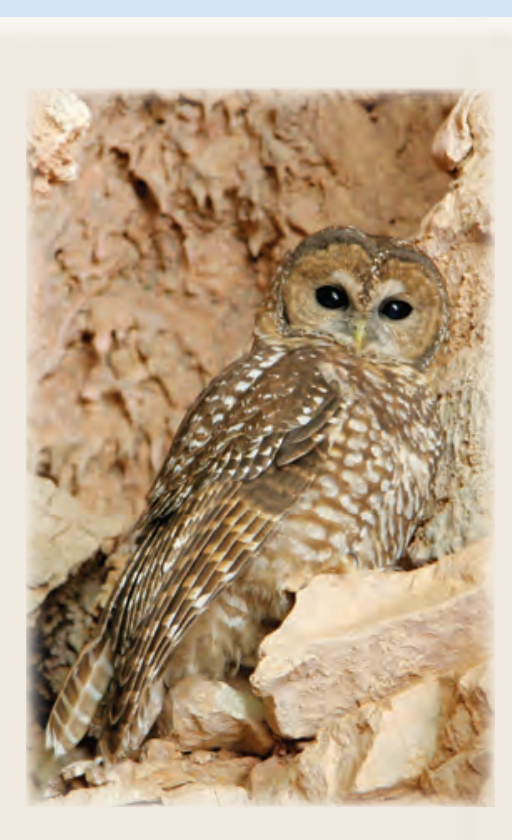

EXPLANATION
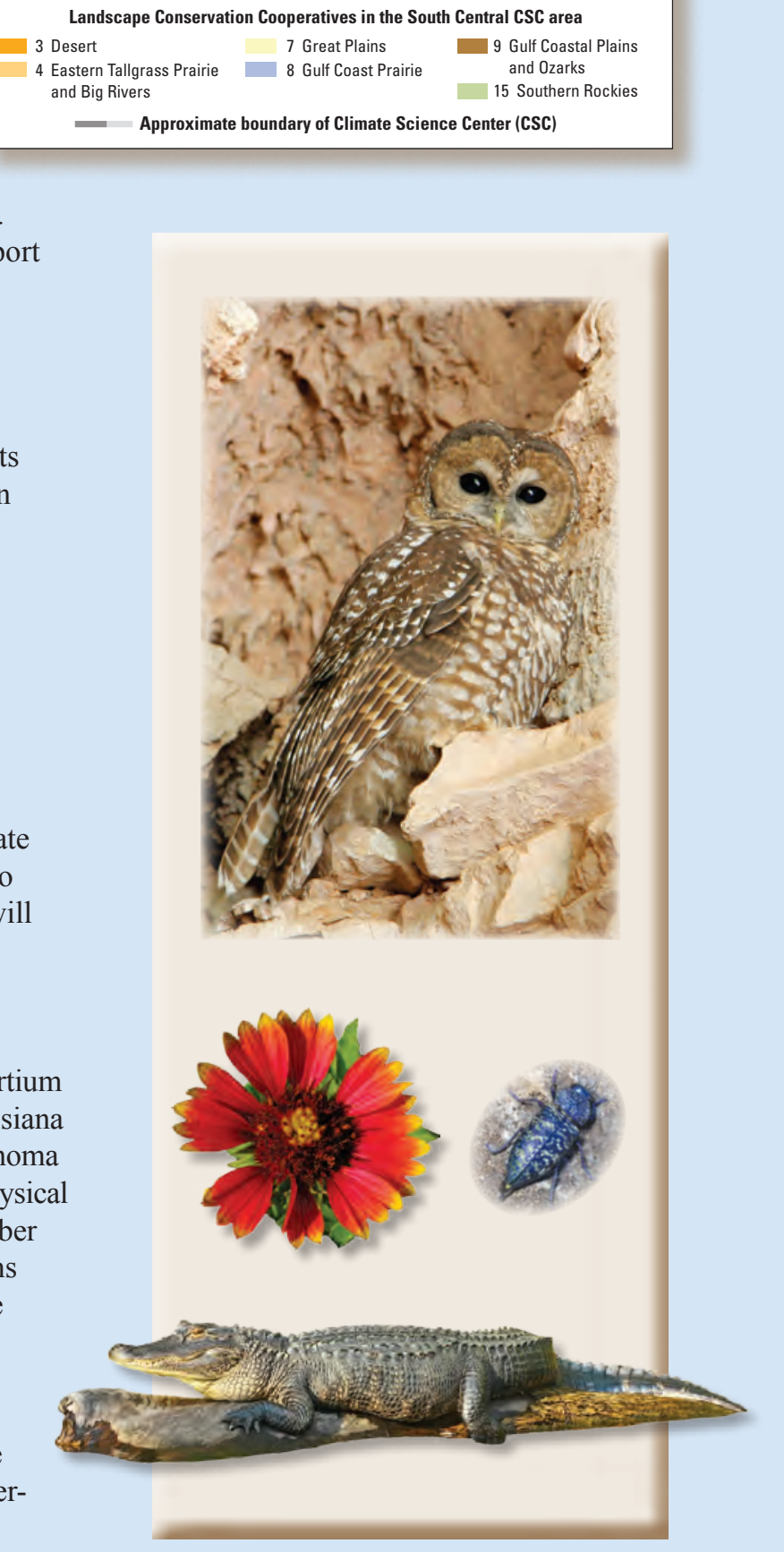


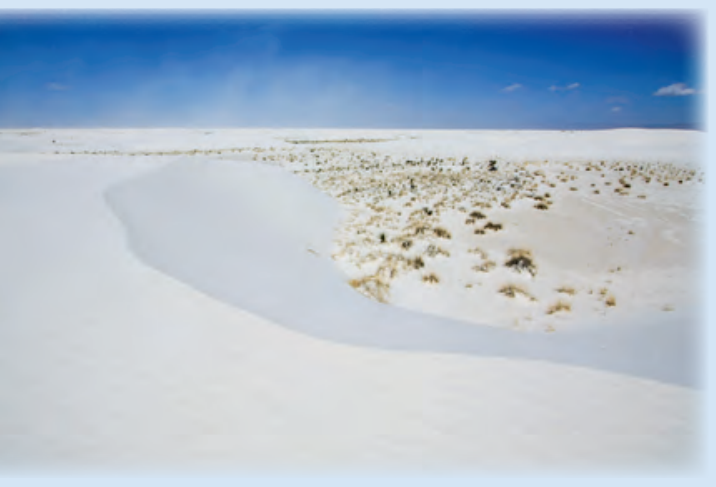

\section{South Central Climate Science Center Consortium}

The current focus of the SC CSC Consortium is on recruiting and training graduate students, conducting climate-change and impacts research, developing climate science and climate-change educational programs, and providing infrastructure for the SC CSC. The focus of the faculty, staff, and graduate students will be their work on climateimpacts science and addressing priority science needs of resource managers while striving to make fundamental advances that have important implications globally.

The Consortium and its partners have expertise in climate science, ecology, impacts assessment, cultural resources, and modeling. This expertise will be needed to prepare for and respond to climate-change issues in the SC CSC region, where changes in temperature, precipitation, and sea-level could have significant impacts on aquatic and terrestrial systems and the diversity of species supported by these systems. The SC CSC Consortium will look to address these potential impacts related to climate change while reaching out across the region and beyond for partners to help fulfill its mission and responsibilities as host institutions.

\section{Science and Stakeholder Processes}

The SC CSC Science Plan will guide the science direction, which is intended to establish high level climate-science priorities and needs and ensure that the science addresses priority management needs. In developing the science plan, the SC CSC will be guided by previously identified priorities of partners and stakeholders in the region. The science plan will be used in determining research funding through the SC CSC and graduate programs or projects that will be developed by the universities.

A Stakeholder Advisory Council (SAC) and a Science Implementation Panel (SIP) for the SC CSC will be formed in 2012. The SAC will be composed of executives from federal and state agencies and tribes to help guide the science planning process and set priority science needs. Although NGOs will not be part of the SAC, their interests are important and will be considered in the planning process. The SC CSC will explore a range of opportunities to gather input from public and private partners.

The SIP will identify specific projects and research teams to address the research priorities identified in the science plan. This panel will be made up of individuals from federal, state, and NGOs who have expert knowledge of the science needed to address climate change.

Representatives from the associated LCCs will be viewed as key stakeholders and principal conduits for communication about management and scientific needs. It will be important for the SC CSC and associated LCCs to collaborate on science needs to ensure that the highest priorities are met, redundancies are eliminated, and significant opportunities are available for sharing resources and communicating climate-science information and needs.

\section{Contact Information}

Kimberly Winton, Ph.D.

Director

South Central Climate Science Center

301 David L. Boren Boulevard, Suite 3030

Norman, OK 73072

Phone 405-325-1272

e-mail: kwinton@usgs.gov

\section{Abbreviations Used in this Fact Sheet}

CSC Climate Science Center

DOI U.S. Department of the Interior

LCC Landscape Conservation Cooperative

NGO nongovernmental organization

SAC Stakeholder Advisory Council

SC CSC South Central Climate Science Center

SIP Science Implementation Panel

USGS U.S. Geological Survey
Photographs by Alan M. Cressler, USGS

Front page:

Strix occidentalis lucida (Mexican spotted owl)

Gaillardia pulchella (firewheel or Indian blanket)

Lampetis drummondi (blue-footed bup)

Alligator mississippiensis (American alligator)

Back page:

White Sands National Monument, Heart of the Sands, Loop Drive, New Mexico

Shelter 888, pictographs, Rough Springs Canyon, Devils River State Natural Area, Texas

El Capitan, Guadalupe Mountains National Park, Texas

Trinity River and Dallas skyline, from south Interstate 45 bridge, Dallas, Texas

Gulf of Mexico, Galveston Island State Park, Texas

For more information please visit http://southcentralclimate.org/ 